\title{
2018 성권리선언문의 준비
}

\section{배정원 ${ }^{*}$}

행복한성문화센터 대표

\section{Seoul Declaration}

\section{Jeong-Weon Bae*}

The Center for Sexuality \& Harmonious Life, Seoul, Korea

\begin{abstract}
The Korean Association for Sexual Health (KAS) announced Seoul Declaration for sexual health in 2003 and 2010. Korean society had been changed radically, therefore it was necessary to develop new Seoul Declaration reflecting social change since 2010. Thus, KAS introduced 2018 Seoul Declaration based on sexual rights declarations of International Planned Parenthood Federation and The World Association for Sexual health, Sexual and reproductive health and rights of UN as well as Seoul Declaration in 2003 and 2010.
\end{abstract}

Keywords: Sex, Health, Right, Declaration, Sexuality

서론

최근 국제사회는 조직 내 성폭력에 대항한 약자들의 연대이며 그들을 위한 격려의 기조에서 비롯된 Me Too 캠페인을 포함해 서 기존의 낡은 성프레임을 걷어가는 방향으로 급변하고 있다. 반면 우리 사회는 성에 대해 더욱 보수화되어 가고, 남녀 와 성적 소수자와 다수자들이 서로에 대해 따뜻한 시선으로 격려하고 응원하며 같이 걷기보다는 혐오와 두려움, 피해의 식을 갖게 하는 여러 부정적인 성문제들이 야기되고 있는 것 도 사실이다.

대한성학회는 창립 15 주년을 맞이하여, 우리 모든 개인들 이 인간 자존감의 기초인 사랑의 주고받음을 통해 더욱 친밀 하고 안전한 관계를 만들어 가는 동시에, 생물로서 갖고 있는 본능적인 생식에의 욕구와 성행위를 통한 즐거움 추구의 욕 구 등을 만족시켜 더욱 행복하게 성생활을 할 수 있도록 목소
리를 내고 건강한 성적 웰빙의 지향점을 제시해야 할 성학회 의 의무에 대해 다시 중하게 인식하였다. 또한 성권리(sexual rights)의 보장이 모든 사람의 존엄, 평등, 자유에 기여한다고 믿고, 성권리는 인권의 중요한 요소라고 확신해 왔다.

이에 대한성학회는 우리 사회가 사람 중심으로 옮겨가는 흐름을 앞서 이끌어가는 학회가 되기 위해 이 사회의 건강한 성문화와 사람들의 성건강을 위해, 사람들의 성건강을 위해 좀 더 진보적이며, 세계와 역사의 흐름에 발맞춰 가고, 여론 을 이끌 수 있는 목소리를 내어야 한다고 생각하여 많은 논의 와 합의를 통해 '서울성선언 2018'을 발표하였다.

\section{본론}

1. '서울성선언 2018'은 지난 2003, 2010년 서울선언으로 발 표되었던 대한성학회의 성선언과 IPPF(International Planned

Manuscript received February 11, 2019; Accepted February 20, 2019

${ }^{*}$ Corresponding author: Jeong-Weon Bae. Kwanghwamoon Platinum Bld. 8F No 820, Jeokseon-dong 156, Jongro-gu, Seoul 03170, Korea. Tel: +82-2-6203-0380, E-mail: byavis@naver.com

(c) Copyright 2019 Korean Association for Sexology

This is an Open Access article distributed under the terms of the Creative Commons Attribution Non-Commercial License (http://creativecommons.org/licenses/by-nc/4.0/)

which permits unrestricted non-commercial use, distribution, and reproduction in any medium, provided the original work is properly cited. 
Parenthood Federation, 국제가족계획연맹), WAS(The World Association for Sexual Health)의 성권리선언, 국가인권위 원회에서 번역한 $\mathrm{UN}$ 의 '성과 재생산 권리 논평(CESCR, 경 제적 사회적 문화적 권리 위원회) 등을 참고하여 초안을 마련 하였다 (1-5).

대부분의 성권리가 개인의 성적 자율권 보장, 섹슈얼리티 (sexuality) 표현의 자유, 차별에 대한 금지와 평등, 폭력에 대 한 금지와 보호, 성교육의 필요, 성건강정보 제공의 보장, 결 혼 등의 삶의 유형과 생식(임신, 출산, 피임, 임신중절, 입양 등의 자녀 양육까지)에 대한 성적 자율성 및 권리의 존중과 보장, 증진 등의 내용을 포함하고 있다.

2. 기존의 서울성선언은 내용이 뜻하는 바가 좀 광범위하 고 막연하고, 남성주의 시각과 함께, 구체적인 함의에 대해 정확하게 알 수 없이 모호한 표현이 있었다. 이에 반해 WAS, $\mathrm{IPPF}$ 등의 성권리선언은 선언의 가치와 입장을 선언 조항 전 에 표명하고, 각 항목에 여러 개의 작은 항목이 구체적으로 표현되는 경우가 많아 참고하였다.

또한 지난번 막연한 표현이나 개인의 사생활에 대한 간섭 으로 느껴지는 부분, 혹은 시민들을 성숙한 성인으로 볼 때 성학회가 너무 좁은 시각을 가지고 계도하려는 것처럼 오해 를 살 수 있는 부분을 고쳤다(2010 성선언, 2, 7, 9).

'성은 애정을 바탕으로 이루어져야 강한 결속을 얻게 되 며 이는 개인, 부부, 가정 및 사회의 건강에 꼭 필요한 부분이 다. 따라서 애정이 결핍된 성행동은 지양되어야 한다.' (서울 성선언, 2010)

2번은 애정을 지향하는 것이 당연하지만, 그외의 관계는 지양해야 한다는 조항이 너무 계도적, 강압적인 것으로 보였 기에 자신의 성을 개인이 자유롭게 책임지게 누려야 한다는 자율적 측면을 강조하였다.

또 현재 우리 사회에서도 결혼/비혼 여부, 출산/입양에 대 한 다양한 방식들에 대한 논의가 이루어지고 있고, 결혼 외 출산에서 태어난 아이들에 대한 사회적 시각의 변화를 요구 하는 분위기라는 것도 고려하였다.
3. '3항. 모든 사람은 자신의 성적 자율성과 고결함을 지킬 수 있도록 타인의 간섭을 받거나, 훼손, 침해당하지 않을 권 리가 있다.'

현재 우리나라를 포함하여 세계에서 일어나고 있는 $\mathrm{Me}$ Too운동은 이미 우리 학회가 Me Too에 대한 대한성학회의 입장`을 성명서로 발표한 바 있기 때문에 따로 항목을 만들지 않고, '성적 자율권이 침해되어서는 안 된다'는 항목에 개념 을 포함시켰다.

'4항. 모든 사람은 만족스럽고 안전하며 즐거운 성생활을 추구할 권리를 가진다.

(중략).... 또한 당사자들 간의 협의에 인하여 이루어진 성 행동은 법적, 사회적으로 최대한 존중받아야 한다.'

그에 반대되는 개념으로 우려되는 '합의에 의한 성관계는 처벌받지 않아야 한다'는 설명을 따로 부연해 넣었다. 성에 대한 어떤 강압도 거부하지만, 이에 대해 지나치게 우려한 나 머지 건강한 남녀의 관계를 침해해서는 안 된다고 보았기 때 문이다.

4. '5. 모든 사람은 자신의 성건강과 관련하여 충분한 정보 를 갖고 책임 있는 결정을 내릴 수 있도록 도와줄 객관적이고 과학적인 성에 대한 정보와 성교육을 제공받을 권리가 있다.'

모든 사람은 자신의 성건강과 관련하여 충분한 정보를 갖 고 자신의 행복을 위한 책임 있는 결정을 내릴 수 있도록 도 와줄 성교육을 받을 권리가 있다.

국제적인 동향을 살펴보면, 1997년에 세계성학회가 13차 학회를 발렌시아에서 개최하면서 발표한 '성의 권리 선언'부 터 성교육을 받을 권리에 대해 이야기되어 왔다. 이후에 성 관련 기관의 국제문서와 선언에 인간의 성을 '성의 권리'와 '성의 건강'이라는 관점에서 이해하고, '포괄적인 성교육을 받을 권리'도 성의 권리 안에 포함하게 되었음을 반영하여 '포괄적인 성교육'이란 표현을 추가하였다. '포괄적인 성교 육'이란, 젠더평등이나 성의 다양성을 포함한 인권 존중을 기 반으로 한 성교육이다. 
유네스코의 '국제섹슈얼리티 교육 가이드'는 2018년 1월 개정판을 내면서 '포괄적 성교육'의 틀을 지금까지의 6개 영 역에서 8개 영역으로 확대했는데, (1) 관계성(가족, 친구, 사 랑, 낭만적인 관계와 데이트, 결혼 및 인생에 대한) (2) 가치, 권리, 문화, 섹슈얼리티 (3) 젠더 이해 (4) 폭력과 안전 보호 (5) 건강과 행복을 위한 스킬 (6) 인간의 몸과 발달 (7) 섹슈얼 리티와 성행동 (8) 성과 생식 건강이다 (6).

‘서울 성선언 2018'에 ‘포괄적인 성교육’을 명시한 것은 세 계적인 성교육의 추세가 포괄적인 성교육으로 가고 있는 방 향을 반영하기 위함이었다.

5. '7항. 모든 사람은 임신, 출산에 대한 결정과 자녀의 수 및 시기, 방법을 결정할 권리가 있다.

또한 임신, 피임, 인공수정, 출산 및 입양과 관련된 생식, 보건서비스의 정보 제공에 접근할 수 있고, 사회 및 의료복지 서비스의 혜택을 받을 수 있어야 한다.' (서울성선언, 2018)

성학회의 공통적인 입장을 정하는 데 가장 많은 논의를 거 쳤고, 발표하는 시간까지 고민을 한 조항이 낙태권에 대한 표 현이었다.

낙태법에 관련된 여성건강권에 대한 이슈가 최근 우리 사 회에 대두되고 있고 이에 대한 사회적 논의가 필요하다.

현재 낙태법 위헌에 대한 청원이 청와대의 게시판에 올려 졌고, 많은 동의를 얻어 논의의 중심에 있다. 낙태를 할 수밖 에 없는 상황에 처한 여성들이 '낙태법'에 걸려 의사와 함께 처벌될 까 두려워 제대로 된 의료혜택을 받지 못하고, 여성의 성건강권을 고심한 끝에 낙태수술을 하는 의사들 역시 처벌 의 대상이다.

그런데 임신을 유발(?)하는 섹스를 함께 한 남성은 전혀 아무런 법적 제재를 받지 않는다. 임신한 여성과 수술해 준 의사만 처벌받는 낙태법은 당연히 문제가 있다.

그렇다고 법대로 낙태를 하지 않고 아기를 낳은 미혼모를 위해 국가와 사회가 하는 일은 거의 없다. 국가가 개인의 실 수(?)인지는 모르지만, 그 사람이 회복되어 사회의 건강한 일 원으로 역할할 수 있도록 도와주어야 할 것인데, 오히려 사회 와 법의 힘을 빌려 개인의 선택권을 억압하고 있는 모양새이 다. 적어도 낙태반대를 주장하려면 미혼모를 위한 사회적 복
지인프라가 마련되어야 한다. 이에 더하여 성교육이 어릴 적 부터 구체적이고 실제적으로 실시되어야 낙태를 줄일 수 있 을 것이다.

우리가 낙태에 대해 더욱 깊이 고민해야 하는 이유는 생 명을 없애는 낙태가 옳아서가 아니라, 태어나지 않은 생명보 다 이미 살고 있는 생명(여성)의 권리와 행복이 우선되어야 하기 때문이다. WAS나 IPPF 등 세계 성관련 학회도 낙태를 허용해야 한다고 목소리를 내고 있으며, 많은 국가에서 낙태 를 부분적으로 허용하고 있는 이유는 여성의 건강권을 보장 하기 위해서이다.

당연하게 임신을 중지할 수 있는 권리에 대한 조항이 있다. 사람의 성적 행복권을 지향하고 이끌어야 할 성학회의 입 장에서 낙태에 대한 논의는 합리적이고, 인본주의적 입장에 서 계속되어야 할 것이라 생각한다.

이에 대해 우리 성학회는 생명권의 존중에 동의하지만, 현 행 낙태법이 여성과 의사를 범죄인으로 만드는 측면이 강하 기 때문에 개정 필요성이 있다는데 의견을 같이 하고 있다. 하지만 학회는 시민단체나 정치단체와는 성격이 다르기 때문에 어떤 입장을 한 방향으로 주장하는 것은 성격에 맞지 않기 때문에 직접적으로 낙태에 대한 언급은 하지 않는 것이 좋다는 의견이 많았다. 그러나 현행법은 여전히 여성인권과 의료권을 제한하는 측면이 강한 문제가 있으며 이에 대해 성 학회는 적극 자문할 용의를 가지고 있다는 입장 발표에는 모 두 동의했다.

6. '8항. 모든 사람은 성과 관련된 어떤 형태의 폭력과 강 압으로부터 자유로워야 하며 보호받을 권리가 있다.

우리는 강간, 성적 학대, 성희롱, 괴롭힘, 성착취를 목적으 로 한 인신매매, 성정체성 및 표현으로 인해 야기되는 폭력 및 강압으로부터 자유로워야 한다.

또한 어떤 상업적인 성착취에서도 보호받을 권리가 있다.'

성매매에 관련하여서는 이미 세계적으로 그 위법성을 논 하기보다는 성매매종사자의 인권과 노동권을 고려하고 존중 하는 분위기이다. 예컨대 $\operatorname{IPPF}$ (세계가족계획협회)는 성노동 자(?)들의 인권과 환경을 보호해야 한다는 관점이고, WAS는 성매매에 대한 항목이 없다. IPPF는 성매매를 인정하고 그에 
종사하는 이들을 성노동자로 규정하여 이들의 인권에 대한 보호를 주장하고 있다.

다만 우리나라는 성매매를 특별법에 의해 불법으로 정하 고 처벌하고 있으며, 성매매 종사자를 피해자라 규정하고 있 는 관점을 가지고 있음을 고려하였다.

그러나 기존의 성선언에는 이미 성매매 배격 조항이 있으 며, ‘금품을 받고 성을 제공하는 행위’라고 표현해 성매매 가 해자의 관점처럼 보이는지라 조항을 바꿀 필요가 있다.

다양한 시각에서 연구가 이루어져야 할 학회라는 차원에 서 성학회가 성매매를 배격한다는 표현을 넣는 것에 대한 이 견들 또한 있었다. 이에 대해 이명화 상임이사의 조언을 받아 '상업적 성착취(Commercial Sexual Exploitation)'라는 말 로 성매매를 포함시켰다.

\section{결론}

대한성학회는 모든 인간의 내재된 자유, 존엄성 및 평등에 의거한 '서울성권리선언 2018'을 발표하고, 모든 사람들의 성권리가 존중되고, 보호, 만족되어야 한다는 것을 천명하며 이를 위해 노력할 것이다.

\section{References}

1. The Korean Association for Sexual Health. 2003 Seoul declaration. http://www.sexology.or.kr/sexology/sub03 03.html

2. The Korean Association for Sexual Health. 2010 Seoul declaration. http://www.sexology.or.kr/sexology/sub03 02.html

3. International Planned Parenthood Federation. Sexual righ ts: an IPPF declaration. https://www.ippf.org/resource/ sexual-rights-ippf-declaration

4. World Association for Sexual Health. Declaration of sexual rights. http://www.worldsexology.org/resources/declaration -of-sexual-rights/

5. United Nations Human Rights. Sexual and reproductive health and rights. https://www.ohchr.org/EN/Issues/
Women/WRGS/Pages/HealthRights.aspx

6. Feminist Journal Ilda. What is 'comprehensive sex education', the trend of sex education in the world? http://blogs.ildaro. com/3397

\section{Appendix}

\section{8 서울선언}

성은 인간의 본질적인 욕구이자 행복의 근거이며, 인권의 중요한 요소이다.

따라서 스스로 성적인 만족이나 쾌감을 건강하게 누리는 것은 개인에게 신체적, 심리적, 지적, 영적, 사회적인 행복의 근거가 된다.

이에 대한성학회는 우리가 추구할 수 있는 최고의 성건강 과 행복을 성취하기 위해, 모든 사람에게 내재된 자유, 존엄 성, 평등에 근거하여 아래와 같은 성권리들이 존중되어야 함 을 다음과 같이 선언한다.

1. 모든 사람은 자신의 성(sexuality, 생물학적 성, 성정체 성, 사회적인 성역할, 성적 지향성, 사랑, 쾌락, 친밀성, 생식 을 포함)의 태도와 행동을 자유롭게 결정할 권리를 갖는다.

개인의 섹슈얼리티를 표현하는 자유는 오직 1) 타인의 권 리와 자유를 보호하고 존중하기 위해, 2) 민주주의 사회에서 공공복지 확립을 위해, 3) 공중보건과 사회질서를 보호하기 위해서만 법에 의해 제한될 수 있다.

2. 모든 사람은 성에서 평등하며 존중받을 권리를 가진다. 성별, 나이, 인종, 종교, 학력, 장애 유무, 성적 정체성과 성 적 지향성, 사회경제 수준, 지역, 결혼 유무 및 가족관계 등에 따른 차별을 받지 않아야 한다. 모든 개인은 법 앞에서 차별없 이 성적 자율권과 자유를 인정받고 보호받을 권리를 가진다.

3. 모든 사람은 자신의 성적 자율성과 고결함을 지킬 수 있도록 타인의 간섭을 받거나, 훼손, 침해당하지 않을 권리가 있다. 
그러므로 성행위 파트너 및 타인의 권리를 충분히 고려한 관계를 전제로 한 개인의 성행위, 성적인 선택을 이유로 괴롭 힘과 학대, 폭력을 당해서는 안 된다.

특히 모든 18 세 미만의 개인은 어떤 종류의 성적 착취에서 도 보호받아야 한다.

또한 자신의 성건강 서비스, 진료기록, $\mathrm{HIV}$ 보균 상태에 관 한 개인정보를 보호받을 권리를 가진다.

4. 모든 사람은 만족스럽고 안전하며 즐거운 성생활을 추 구할 권리를 가진다.

우리는 즐겁고 만족스럽고 안전한 성적 경험을 얻을 수 있 는 성생활을 지향하며. 성취할 수 있는 최고 수준의 성건강과 행복을 누릴 권리가 있다. 이를 위해 파트너를 선택하거나, 언제, 누구와, 어떻게 성관계를 하거나, 하지 않거나 간에 모 두 상호간의 자유롭고 기꺼운 합의를 통한 것이어야 한다.

또한 당사자간 상호협의에 의하여 이루어진 성행동은 법 적, 사회적으로 최대한 존중받아야 한다.

5. 모든 사람은 자신의 성건강과 관련하여 충분한 정보를 갖고 책임있는 결정을 내릴 수 있도록 도와줄, 객관적이고 과 학적인 성에 대한 정보와 성교육을 제공받을 권리가 있다.

우리 모두는 성건강에 관련된 과학적인 진보와 적용의 혜 택을 누릴 권리를 가진다. 자유롭고 충분한 정보와 교육을 바 탕으로 성행동을 결정할 수 있도록 성 관련한 과학적이고, 객 관적인 정보와 교육을 제공받을 수 있어야 한다.

포괄적인 성교육은 적절한 연령대에게 성욕과 쾌락에 대 한 긍정적인 시각으로 시작되어야 하며, 인권, 성평등 및 성 욕과 쾌락에 대한 긍정적인 접근방식을 기반으로 해야 한다.
6. 모든 사람은 결혼 및 기타 유사한 유형의 관계를 책임있 게 선택하고, 결정하며, 해체할 권리가 있다.

우리는 결혼 및 기타 유사한 관계에 대해 어떠한 차별이 나 배제없이, 자유롭고 완전한 동의 하에 선택, 시작, 성립, 해산할 때 동등한 권리를 누릴 자격이 있다.

우리 모두는 자신의 가족 형태와 상관없이 가족과 관계된 사회복지 서비스를 받을 권리가 있고, 혈통과 결혼과 무관한 사람들을 존중해야 한다.

7. 모든 사람은 임신, 출산에 대한 결정과 자녀의 수 및 시 기, 방법을 결정할 권리가 있다.

또한 임신, 피임, 인공수정, 출산 및 입양과 관련된 생식보 건 서비스의 정보 제공에 접근할 수 있고, 사회 및 의료복지 서비스의 혜택을 받을 수 있어야 한다.

8. 모든 사람은 성과 관련된 어떤 형태의 폭력과 강압으로 부터 자유로와야 하며 보호받을 권리가 있다.

우리는 강간, 성적 학대, 성희롱, 괴롭힘, 성적 착취 및 노 예, 성착취를 목적으로 한 인신매매, 성 정체성 및 표현 등으 로 인해 야기되는 성관련 폭력 및 강압으로부터 자유로와야 하며 보호되어야 한다.

또한 어떤 상업적인 성착취에서도 보호받을 권리가 있다.

9. 국가는 개인의 성 권리 실현을 위하여 정책을 수립하고 이를 보호하고 존중할 의무가 있다.

국가는 개인의 성권리 실현을 위하여 보호하고 존중할 의 무가 있다. 이 의무에 따라 국가는 성권리의 완전한 실현을 위해 적절한 조치를 취해야 한다. 